\title{
Factors influencing the dietary intake of military members in the Canadian Armed Forces working in the Arctic
}

\author{
F. Lavergne 1 , I. Giroux ${ }^{2}$ \\ 1 Interdisciplinary School of Health Sciences, University of Ottawa \\ ${ }^{2}$ School of Nutrition Sciences, University of Ottawa
}

Introduction: Military members in the Canadian Armed Forces (CAF) do not consistently meet their daily energy needs with combat rations when working in harsh environments, like the Arctic (1, 2). Low dietary intakes over a prolonged period can contribute to involuntary weight losses and diminished performance, and increase the risk of injury (3). Many factors are thought to influence soldiers' dietary intake $(2,3)$.

Objectives: This study aimed to determine CAF members' perception of individual, dietary, and environmental factors influencing food intake while working in the Arctic.

Methods: A survey was sent nationally with SurveyMonkey July-September 2018 to military members who worked in the Arctic 2015-2018. The survey included questions on demographics, physical markers, acceptability of rations, eating habits, and diet history during Arctic work. The 20-minute survey had 39 open and closed-ended questions, including some on food variety, amount of food eaten, time for meals, ability to heat rations, hunger, and weight changes. Excel was used to compile descriptive statistics.

Results: The survey response rate was $27.5 \%$. Soldiers $(n=37)$ and instructors $(n=11)$ participated (ages $31.7 \pm 7.2$ years; 45 men, 3 women). They reported that $61 \%, 68 \%$, and $71 \%$ of breakfast, lunch, and supper rations were eaten. Two participants reported not having enough time to eat [Figure 1]. Eating on the move, weather/environmental conditions, and equipment required for food preparation and consumption were factors that negatively affected the most dietary intake of military members during Arctic exercises. Sixty-five percent $(n=31)$ self-reported losing weight during their exercise $(1.8-11.3 \mathrm{~kg})$.

Conclusion: Preliminary results showed that many factors influenced the dietary intake of CAF members working in the Arctic. Lack of time did not seem to limit intake. More research is needed to accurately measure weight change during these exercises, and explore options to make rations better adapted for the Arctic.

Significance to the field of dietetics: These results may help dietitians develop rations better suited for this population.

\section{Figure 1. "Did you have enough time to eat your ration?" (n=47)}

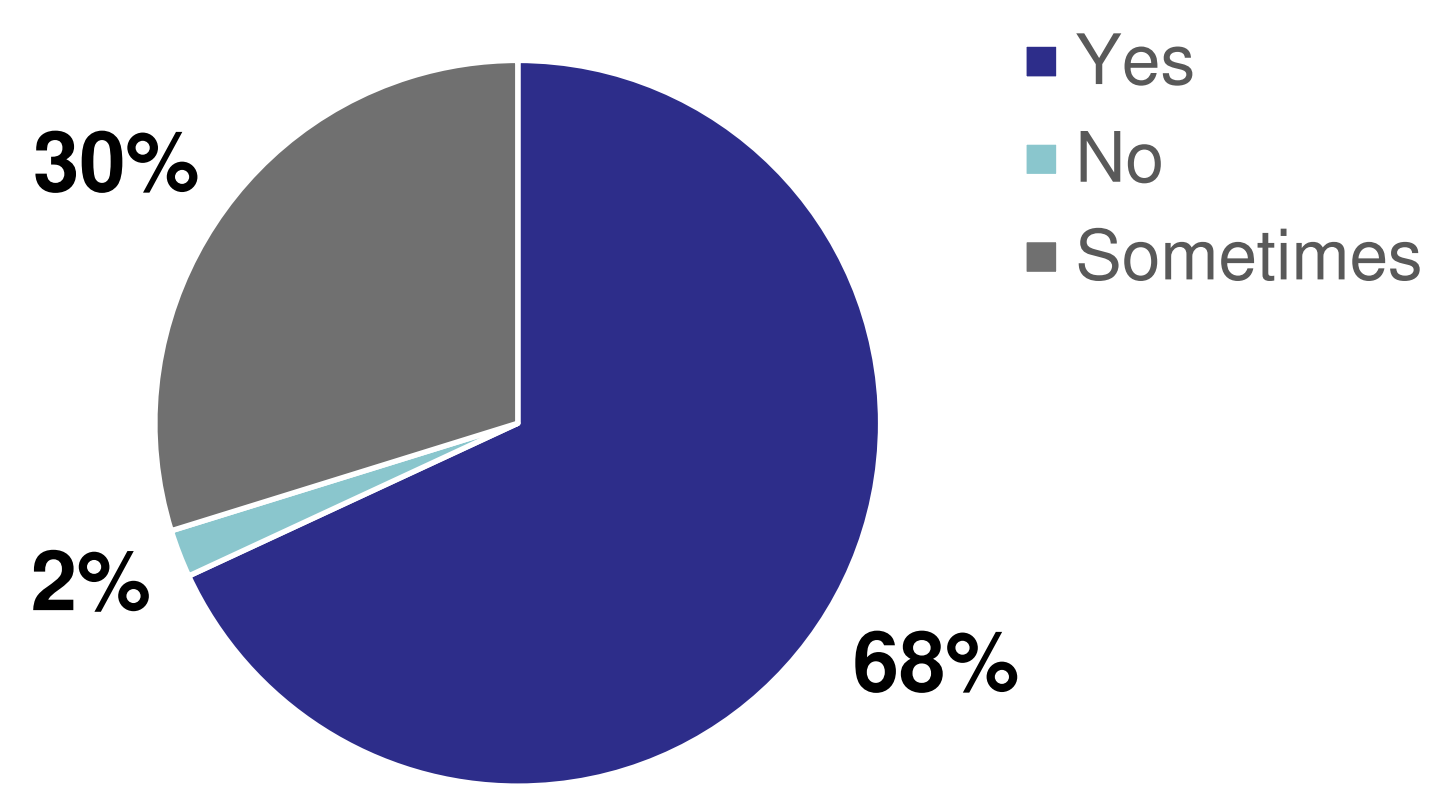

1. Goodman, L., Sullivan-Kwantes, W., \& Blais, A. R. (2015). Observations and survey results of army field feeding in the Arctic: Arctic field feeding logistics and effectiveness (scientific report $n^{\circ} \mathrm{R} 289$ ). Defense Research and Development Canada - Toronto Research Centre.

2. Mandic, I., \& Jacobs, I. (2013). Field-feeding for CF land military operations: Basic guidelines for standard and incremental allowances for food service providers (rapport de contrat $\left.n^{\circ} 104\right)$. Defense Research and Development Canada - Toronto Research Centre.

3. Committee on Military Nutrition Research. (1995). Not Eating Enough: Overcoming Underconsumption of Military Operational Rations. Marriott, B. M. (éd.). Institute of Medicine. National Academies Press. Washington, USA.
I would like to thank Pre Isabelle Giroux for her consistent help throughout this project, as well as the Canadian Armed Forces for their support and cooperation in this study, especially Lynda Hinch. 